\title{
مسرح الكباريه السياسي وتمثلاته في عروض كاظم النصار
}

أ.م.د. زينة كفاح علي الثبيبي

جامعة بابل / كلية الفنون الجميلة

\section{dr.zina20@yahoo.com}

\author{
تاريخ الاستلام : 14-02-2021-16 \\ تاريخ القبول : 16-03-2021
}

ويعد المخرج العر اقي (كاظم النصار) منتجاً لرهطٍ من العروض التي اتخذت سمة الكباريه السياسي وما لحق بالذات العر اقية من أزماتٍ وآثار حروب وحضارات، كان لها محمولاتها من العلامات والمعالجات الخاصة بالأزمات، ليكون لها امتياز ها في الطرح وقر اعة الو اقع أثر الهزات المجتمعية المتلاحقة. جاء البحث بأربعة فصول تضمن الفصل الأول (الإطار المنهجي للبحث) ومشكلة البحث المتسائلة عن: الكباريه السياسي في عروض المخرج كاظم النصار المسرحية؟ وتجلت أهمية البحث و الحاجة إليه في: أ. استجابة المخرج العر اقي ومسايرته لأحداث الحياة اليومية وأزماتها وتحو لاتها.

$$
\text { ب. يفيد البحث المعنيين في الإخر اج المسرحي. }
$$

ت. أما هدف البحث فقد سعى إلى : كثف الكباريه السياسي في عروض المخرج العر اقي (كاظم نصار). وجاءت صور البحث فقد أتى الحد الزماني للفترة بين (2014 - 2017) و الحد المكاني: كان معنياً بـ بغداد / العر اق. وحمل الحد الموضو عي: مسرح الكباريه السياسي في عروض المخرج العر اقي كاظم النصار المسرحية. وجاء الفصل الثاني (الإطار النظري) شاملاً على مبحثين: أو لاً: مرجعيات عروض الكباريه السياسي. ثانياً: عروض مسرح الكباريه السياسي عربياً وعر اقياً. وختم الفصل بمؤشرات الإطار النظري . و أتى الفصل الثالث متضمناً إجر اءات البحث و هي: أو لاً: عينة البحث، إذ شملت عروض (أحلام كارتون وسينما)، ثانياً: أداة البحث، اعتمدت مؤشرات الإطار النظري كأداة لتحليل عينة البحث. ثالثا: منهج البحث، اعتمد المنهج الوصفي التحليلي في تحليل العينة. أما الفصل الر ابع، فقد تضمن أو لاً: النتائج، ثانياً: الاستنتاجات، ثبت المصادر و المر اجع ثم الملخص باللغة الانكليزية. الكلمات المفتاحية: الكباريه السياسي، تمثلات 


\title{
Features of the political cabaret theater in the shows of Kazem Al- Nassar
}

\author{
Assist. Prof. Dr.Zina Kifah Ali Al-Shibeeby \\ University of Babylon
}

Receipt date: 2021-02-14

Date of acceptance: 2021-03-16

\section{Abstract}

The Iraqi director (Kazem Al-Nassar) is a producer of shows that took the characteristic of political cabaret and what befell the Iraqi self in terms of crises and the effects of wars and civilizations, which had its loads of marks and treatments for crises, to have the distinction of presenting and reading the reality of the successive societal shocks.

The research came in four chapters, which included the first chapter (the methodological framework for the research) and the research problem asking about: The features of the political cabaret in director Kazem Al-Nassar's theatrical performances? The importance and need for research were evident in:

a. The Iraqi director's response and his equilibrium with the events of daily life, its crises and transformations.

b. Useful research concerned in theater direction.

c. As for the aim of the research, it sought to: Expose the features of the political cabaret in the shows of the Iraqi slasher (Kazem Nassar).

The images of the research came as the temporal boundary of the period between (20142017) and the spatial boundary came: it was concerned with Baghdad / Iraq. He carried the objective limit: the features of the political cabaret theater in the theatrical performances of the Iraqi director Kazem Al-Nassar.

The second chapter (the theoretical framework) includes two topics:

First: References to the political cabaret show.

Second: Arab and Iraqi political cabaret theater performances.

The chapter was concluded with indicators of the theoretical framework.

The third chapter includes the research procedures, namely:

First: The research sample, which included presentations (cartoon and cinema dreams). Second: The research tool, the researcher relied on the theoretical framework indicators as a tool to analyze the research sample. Third: Research methodology, the researcher adopted the descriptive and analytical approach in analyzing the sample.

As for the fourth chapter, it included first: the results, second: the conclusions, establish the sources and references, then the abstract in English.

Keywords: political cabaret, representations 
تتمثل حساسية المسرح بترصده ومعالجاته لظروف حياتية تخص و اقع الأحداث المعاشة، مقترحاً بعض الإشار ات حلو لاً لمشاكل

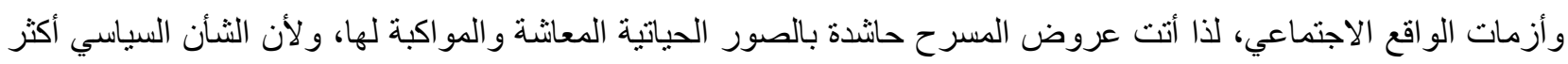
حضور اً من الأفكار والأداء في التأثير والتأثر والمساس بالحياة الإنسانية جاءت استجابة العروض المسرحية للظروف السياسية

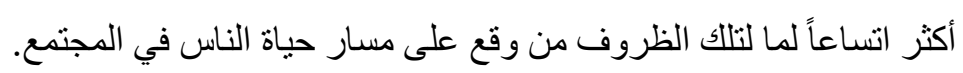
وشهد المسرح بنصوصه وعروضه على تلك المعاينة والحالة السياسية ما يتطلب عدةً ومنظومةً لقر اءة الحدث السياسي، فكان لمسرح الكباريه قدر اته في مو اجهة الظرف السياسي و التحريض على النتائج التي انتهت إليها ظروف الحياة الاجتماعية عموماً، و واستلزم ذلك استنفار اً من الأفكار و التقانة لفريق العمل المسرحي. وكان إن استعان مسرح الكباريه السياسي، وبهدف سرعة الاستجابة للأحداث استعان بمنظومة من الفنون الأدائية والوسائط

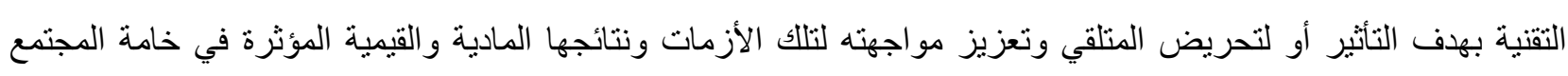
عامةً.

ويعد مسرح الكباريه إنتاجاً محدثاً شهدته ظروف الاهتزازات السياسية للفرد العربي ما يبرر حضوراً لأنواع من المسارح و التناصات و الاستعار ات الأدبية و الفنية و الجمالية ما شكل شعرية كاملة لهذا النط المسرحي. إن مسرح الكباريه السياسي لا يأنف من التقاط الهو امش والمضمرات وشذرات النصوص و الصور ورفعها إلى فضاء المسرح لأنه معنيٌ بما هو يومي ومعاش، ومن هنا جاءت مشكلة البحث منسائلة عن: مسرح الكباريه السياسي وتمثلاته في عروض ولثن

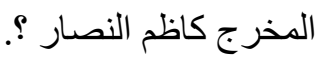
ثانياً: أهمية البحث و الحاجة إليه 1. استجابة المخرج العر اقي ومسايرته لأحداث الحياة اليومية بمجمل تحو لاته. 2. يفيد البحث المعنيين بالإخر اج المسرحي في معاهد وكليات الفنون الجميلة. ثالثاً: هدف البحث : بـ كثف الكباريه السياسي وتمثلاته في عروض المخرج العر اقي كاظم النصار. رابعاً: حدود البحث 1. - الحد الزماني: 2014-2017. 2. الحد المكاني: العراق / بغداد. 3. الحد الموضوعي: مسرح الكباريه السياسي وتمثلاته في عروض المخرج العر اقي كاظم النصار. تحديد المصطلحات: 
صيغة مسرحية شعبية عالمية استمدت تكوينها الفني وركائزها التقنية من عدة فنون متشابهة، اشتركت معاً في معالجة

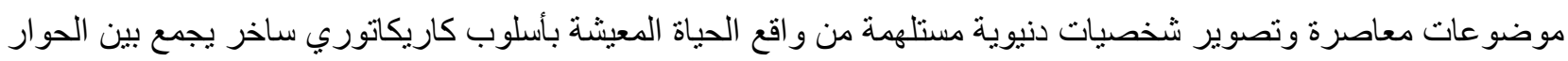

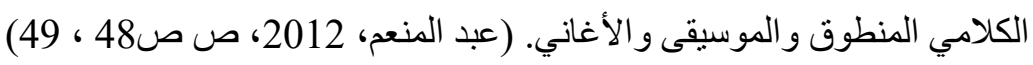
التعريف الاجرائي: اتجاه مسرحي معاصر يقوم على معالجات لاحداث يومية معاثة بصيخ التهكم و العجائبية والمفارقة، وبأسلوب نو اصلي يتوسل بالملفوظو النصوص الاشهارية و التسجيلية و الموسيقية. الفصل الثاني

$$
\text { المبحث الأول: مرجعيات مسرح الكباريه السياسي }
$$

تعد الفنون باختلاف أجناسها و أنماطها وتبار اتها التاريخية في حالة تأثر ونأثثر متبادل سواءً في داخل الجنس الواحد أو مع مجمل الفنون الأخرى المجاورة. ففي متن على نصٍ، هناك ما يؤشر تأثره بنص سابق من ذات الجنس او خارجه، وهو ما يشيع أسلوباً و اتجاهاً عرفته النظريات الادبية والجمالية بأسم (التناص). وفيه يكون النص حاصلاً لمجموع من النصوص التناريخية و المعاصرة في أفكار ها وبنائها وطرق نواصلها مع المتلقي ذاته. ويشترط التناص في آلياته أن يكون للنص بعض ولنه التدشين

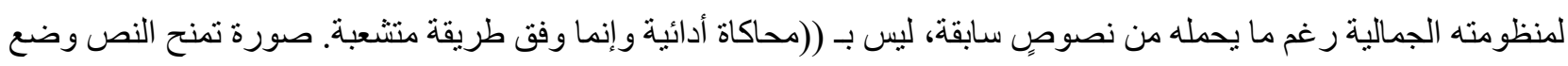

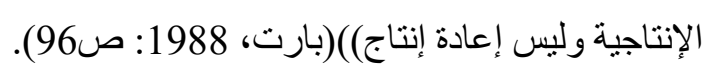

وتأتي الشعرية هنا ليكون للنص ذاته ومستوياته من الجدَّة وتجاوز النص الأصل عبر كونها ((فئة عامة من الصلات تشمل إثكالاً شديدة التنوع مثل المحاكاة الساخرة Parodie السرقة playiat الكتابة من جديد yeecrirure الالصاق collage ... لكن اذا ما كان كل عمل هو تتاص يمكن حينذاك تميز اختلاف في درجة الانعكاس. بعضها موسوم صراحة بعمل سابق. يشير بصفة

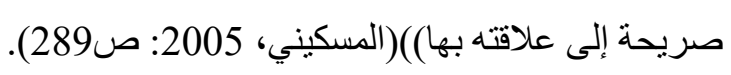

وتؤشر سجلات تاريخ فن الإخر اج مراحل تجريبية ومدارس عمدت إلى تفعيل مستويات الأداء المسرحي فيما يخص البنية الداخلية للعرض، أو سبل نواصله مع المتلقي وفقاً لوقائع الحياة والأزمات و الأفكار وخصائص الذائقة الجمالية، إن المسرح السياسي الذي شرع في الظهور على الساحة الذوقية والإخر اجية و الفكرية يعد واحداً من الاتجاهات الإخر اجية التي شغلت مساحة في التميز بما دشنه من سبل لإيصال الفكرة إلى جموع المتلقين بهدف تفعيل الاستجابة الفكرية و الجمالية لديهم ودعوتهم من بعد إلى اتخاذ موقفٍ حيال ما يقدم في الفضاء المسرحي و التوسل به لقر اءة وكثف الحياة المعاثة من قبل الذات الإنسانية وتوسل المسرح التسجيلي بمنظومة من الوسائط والأفكار في اعتماده أسلوبية العرض المسرحي ((القائم على المباشرة و الفعلية و التصميم و إنشر الك الجمهور و الميكانيكية الجديدة للاتصال، أو إلى الإقلال من أهمية دور المنطق اللفظي)) (عبد الحميد، 2013:

ولعل و احدة من أهم عو امل تنشيط خطابات المسرح السياسي هو ما استجد من ظو اهر اقتصادية وتقنية فيما يخص صناعة الثقافة وسبل تسويقها وهو ما انعكس على مجمل الفنون للعقود الثثاثة الأولى من القرن العشرين مثل (السينما، المسرح، الموسيقى، الرسم، الثعر ، العمارة)، حيث ((غير تطور وسائل إعادة الانتاج وامكانات الانتشار الواسع و انتفاع جمهور متزايد من جميع

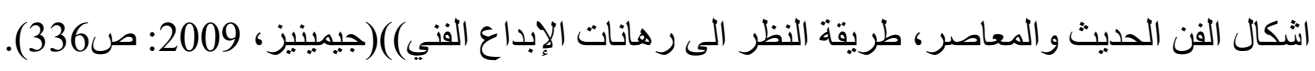


و هو ما استجاب له المخرج الالماني (ايرفن بسكاتور 1893 - 1966) في رؤيته للمسرح ومعالجاته لقضايا الانسان في قرن التقنية و هيمنة الآله و الصناعة وتفعيلها داخل منن الفضاء المسرحي، ففي مقالته المعنونة (يمكن للمسرح أن ينتمي لعصرنا) يجد (بسكاتور ) تقنيات الصوت و الثريط تسهم في إثر الك الجمهور في صناعة وتشكيل خطاب العرض المسرحي، إذ يرى ((إن البحث في الصوت يقدم لنا إمكانات غير حضوره في استخدام الموسيقى والمؤثرات الصوتية في المسرح. فعرض الصور المتحركة على الثنانثة واداة التلوين و التبادل المتقابل بين الضياء وبين (ضياء الفيلم) وتحريك الخشبة على نحو متكامل من خلال هذه الوسائط و العديد من الوسائل الأخرى هو ما استجده العلم الاخلاق. ليحل محل صندوق الدنيا القديمة. فماذا سيحدث اذا كان

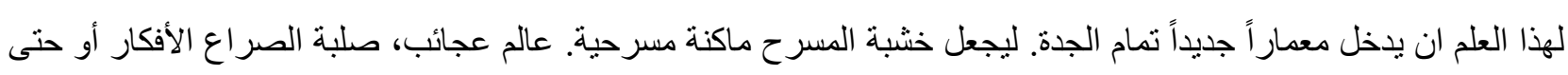

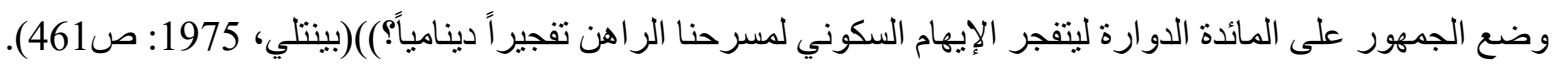
كما تتهض الفعالية الاتصالية بسمات التداولية بين طرفي التراسل في المسرح لدى (بسكاتور)، مؤكداً ((أنت لديك رسالة ورسالتك أن تقنعني وعن إقناعك لي عليك أن تصبح معلمي الى أن تصبر فناً جماهيرياً يقترب في معالجاته من أزمات المجتمعات الاقتصادية والاجتماعية لينتهي أي الفن المسرحي لدى (بريخت) الى ما ((هو جماعي عمومي جماهيري حبوي حر

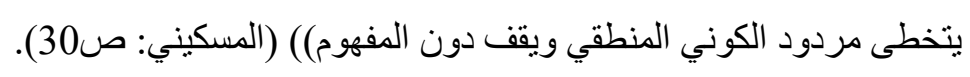

وجاءت نظرية المخرج (برونولد بريخت 1898 - 1956) ومعجمها الدلالي تعكس واقعاً حياتياً وحقبة تاريخية معبرة عن جملة تغير ات شهدتها عقود الثناثينيات من القرن العشرين ما انعكس على آلية بنية وماهية الفن وسبل نو اصله مع المتلقين والوسائط

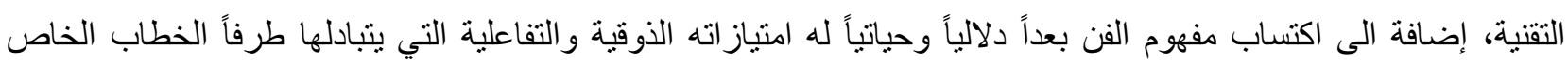
العرض المسرحي لدى (بريخت) على الأقل: إذ ((يمكن تصنيف الفاعليات الادائية والتواصلية والاستر اتيجية بكونها فاعليات عملية تهدف الى إنتاج شيء من الخارج لوقائع وحقائق غلاف تأملية (النظرية و الذاتية) التي قد تنتج انعكاسات ذاتية أو جو انية،

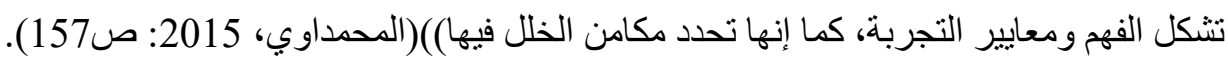
و هو ما استدعاه الخطاب المسرحي لدى المخرج (بروتولد بريخت) المقولات النظرية في المسرح الملحمي منطلقاً من إسهام المتلقي. ولذلك يسعى خطاب العرض المسرحي لدى (بريخت) إلى استتهاض مقدرات المتلقي وتتشيط يقظته حيال ما يجري ويؤدي داخل فضاء العرض وبعد انتهائه حين يشير (بريخت) الى جعل العرض خطاب العرض متناً للتعبير و الجدل من الأفكار و المعاني

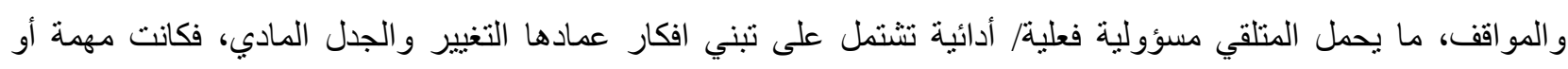
(وظيفة المسرحي توعية الجماهير فكرياً في إطار ايديولوجيا معينة حتى يدفعهم من خلال هذا إلى الفعل السياسي خارج المسرح أي أن وظيفة الاداء المسرحي هي تحويل المشاهدين إلى مؤدين على مسرح الحياة ينشدون فعل التغيير ويسعون إلى تحقيقه))

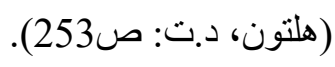

ويستدعي العرض المسرحي لدى (بريخت) عناصر العرض السينوغر افية المألوفة بستدعي عنصري الموسيقى والغناء في تعزيز مسوغات البناء والاتصـال مع المتلقي عبر التقطيع الحدث إلى الواح. ويأتي عنصر الموسيقى و الغناء بهدف دفع المنلقي الى كثف اللعبة المسرحية، بما يحمله النص الموسيقي من قدرات تعبيرية في الكثف عن الأفكار والثنمات الهادفة إلى تغيير موقف أو مو اقف المتلقي، حيث تكثف النصوص الموسيقية والغنائية عن تناقض أحياناً ومسار الحدث ما يبرر للمنلقي ان يقف 
على لحظة التثاقف تلك إذ (تتقاطع الاغنيات مع الحوار بصورة دائمية فتعمّق دلالة الموقف في احيان وتعد تعارضه معارضة

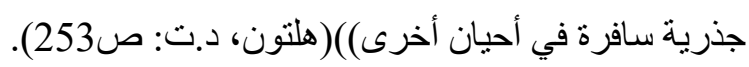
كما انفتح الفن المسرحي في منظومته الفنية على جملة تقنيات لها سماتها في (الإشهار ) و الإعلان و البنى الاتصالية الأخرى حيث تم توظيف بعض التقنيات التي اعتمدتها نصوص الدعاية أو الاعلان و الصور و البر امج في فضاء المسرح. ففي مجتمع الصورة و الفضائيات التي استجاب وتثاقف معها العرض المسرحي ((فكل شيء أصبح بالضرورة موضوعاً للإشهار. ولا وجود نشاط

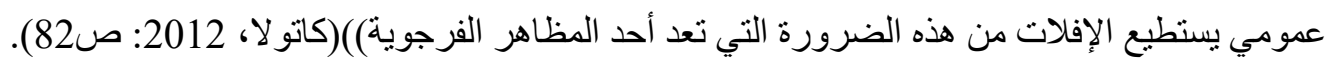

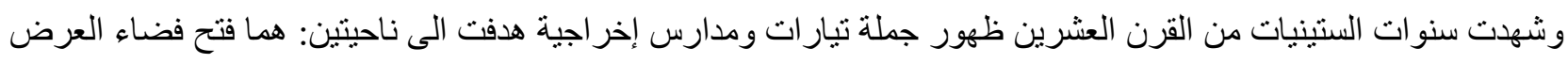
المسرحي على مو اقع وأمكنة لها تنوعها الجغر افي ما اتاح تحقيق الخاصية الثانية وهي التفاعل المادي مع الجمهور، كما في عروض بيتر بروك و الثمس و عروض المسرح الثالث. وفيها يأخذ الجمهور دور اً ادائياً في العرض المسرحي من حيث التشكيل

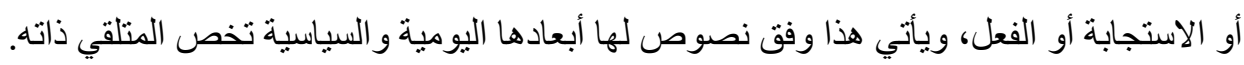
ويجد المخرج (اوجينيو باربا 1936- ) وفق ذلك، إن المسرح ((ليس محض نتاج. إنه يخلق علاقات بين الناس)) (إفنز، 2007: ص250).

و انفتحت مجمل الاتجاهات الإخر اجية في هذه المرحلة على نصوصٍ الانثرولوجيا في ثقافات الأمم والثعوب، في خطوةٍ لكسر إطار التقليد المسرحي. وأتاح ذلك اسهام المتلقي في الاستجابة للعرض بصيغ الفعل او الحركة، كما في تجارب (بيتر بروك 1925- ) المسرحية، وتجارب أخرى تم فيها توظيف الانثرولوجيا بعدِّها مصدر اً اولياً للعمل المسرحي، بأثر ما يحمله من

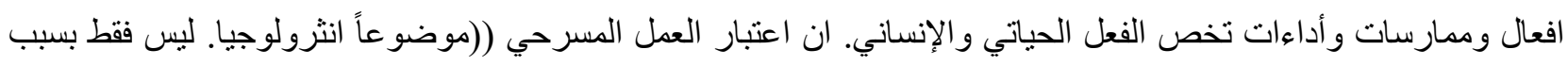
طبيعة موضو عه الاجتماعي. اللساني الرمزي والمعقد ولكن كذلك بسبب الإجر اءات والخطوات المتبعة في صياغته))(بلال، 2011 : ص102)

وفي هذا الاتجاه يأخذ العرض المسرحي معالجات الوقائع اليومية دون التمايز الواقعي والخيالي واللعبي ((إن التقليد الحديث في مجال الانثرولوجيا والتحليل النفسي يقترح أن مجال اللعب لا يتداخل مع الواقع بعدة طرق مهمة فقط بل هو كثثر اً ما يستخدم كبوتقة نجد فيها المادة التي نستخدمها ونطوعها ونستخدمها في أشكال جديدة ذات مغزى في العالم الحقيقي للنشاط

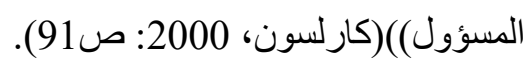

وتنفتح العروض المسرحية بهدف تفعيل دور الفن المسرحي في الحياة عموماً إلى التقنيات العلمية لإيصال رسائلها الى جموع المتلقين، و هو تواصل يتناص وطروحات المسرح السياسي لدى المخرج (بسكاتور). فالعرض المسرحي وعبر تقنية الثانشات التي نتغل جزءاً من العرض المسرحي وسيطاً تعبيرياً بين جمهور المتلقين وفضاء العرض، وفيها يتم تجاوز المسرح الإيهامي

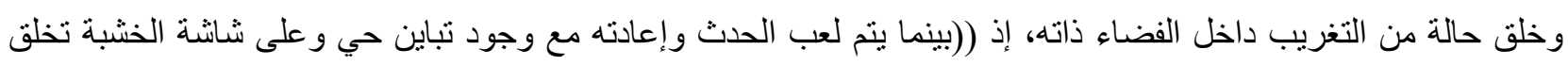

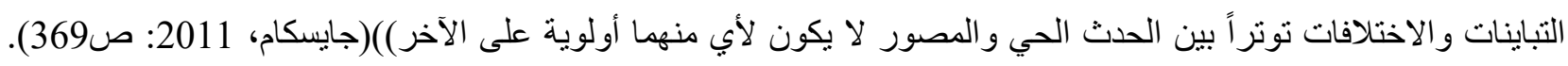
كما يسعى العرض المسرحي إلى تجاوز الحدود القائمة بين الحياة و الفن ذلك بسبب ان ((فئات الواقع و غير الواقع غير كافية اليوم

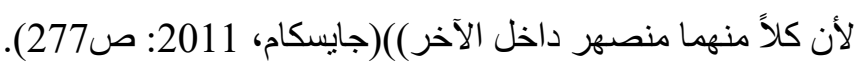
ونجد في مستويات التفاعل بين العرض بكل ما يحمله من منظومة ادبية وفنية وتقنية ينتهي لدى المتلقي بالإحالة الى الظرف الاجتماعي و السياسي القائم. 


\section{المبحث الثاني: عروض مسرح الكباريه السياسي عربياً وعراقياً}

اولاً: عربياًَ

يتسم فن المسرح بعّده شاهداً حياتياً على تحو لات وأحو ال الذات الإنسانية كونه فناً جمعياً شاملاً سواءً في بنيته النصية وطرق تو اصله مع المتلقي. فكانت الاتجاهات و التيارات المسرحية والإخر اجية في مواكبة للأحداث السياسية و الاجتماعية و الاقتصادية والثقافية التي شهدتها حقب التاريخ الانساني عموماً. وفي وطننا العربي وفي شاهدة مفصلية تعد هزيمة الخامس من حزيران/ 1967، في آثارها على الذات العربية، فما قبل حزيران ليس كما بعده من حيث الفكر والادب والثقافة والسلطة السياسية و الخطابات الايديولوجية، فالهزيمة أتت عاصفة وشاملة في اهتزازاتها للوجود العربي بكليته فكان أن أنعكس ذللك على الخطاب المسرحي وامكانياته من الثفافية في تدارك وقر اعة بنيته الفنية ومنظومته الثيماتية وأشكال نو اصله. إذ ظهرت للمشهد المسرحي العربي اتجاهات وتيارات عدة لقراءة آثار الهزيمة بعناصر في التعبير و البناء والرفض واقتراح بعض الحلول ويمكن إجمالها بالتالي(الخر اط، 1993: صبربي 15-20): 1. تبار التشيؤ:- أو التبعيد أو التغريب:- .... تقف فيه الأشياء، والأشخاص الذين اوشكوا ان يصبحوا -بدورهم- كالأشياء، مقررة، موضو عة كأنها لذاتها، وكأنها لا تعنى و لا تدل على شيء آخر غير ذاتها. 2. التيار الداخلي... يخلي الساحلة الواقعة مكانية زمانية معاً، تتر اكب فيها أمكنة الداخل وأمكنة الخارج معاً، وأزمانهما معاً، الجيشان و المتعقد و التمزق في سياق الرؤية واللغة... 3. تيار استيحاء التراث العربي التقليدي، التاريخي، او الثعبي: حين يظفر... بشريان الفليكلور، أو يبعث الحكاية الثعبية ويمنح حالياً من رصيد غني في الذاكرة الجماعية للناس. 4. التيار الو اقعي (السحري) أو تبار الفانتازيا والتهاويل: حيث تسقط الحدود بين (ظاهرية) الو اقع العيني المرئي المحسوس، وبين شطحات الخيال و الاستيهامات المضفورة أحياناً بنسيج الواقع. 5. و اخيراً التيار الو اقعي الجديد: ... فالموقف هنا ــائماً. هو موقف رفض السلطة التقليدية. والرؤية هي ـأساساً. مسألة نظام القيم السائدة -الثكل وان كان مأخوذاً من الرصيد التقليدي إلا إنه يختلف عنه إختلافاً جو هرياً. ويرشح من كل ذلك اشارات تخص بنية النص المسرحي، فالهزيمة شاملة بضروب حياة الثعوب العربية دون اقتصار ها على طبقة أو فئة أو ثقافة، لذا اتت شخوص المسرحية حاملة الصفة الجمعية دون بطولةِ ما، إضافة الى منح الثخصيات المهششة دوراً في مو اجهة السلطات السياسية وخطابها الآيديولوجي و البحث من بعد عن حلول تر اها أقرب إلى التفاؤل إزاء المستقبل ذاته في سعي الثخصيات إلى تخطي الواقع بدلاً من حالة الثكوى والتمرد السلبي للأبطال التي كرستها المقولات الوجودية والشار ات الماركسية.

و عروض مسرح الكباريه السياسي بالوطن العربي لها تنو عها في مسايرة آثار هزيمة حزيران التي استمرت لعقدين لاحقين السبعينيات والثمانينيات، حيث طرحت وحملت العروض معالجات عدة ولها تتوعها في البنى و الوسائط الفنية بحثاً عن مفهوم متحرك سعت إليها الذات العربية طويلاً مثل (الهوية) و التي ((تقوم على الوحدة التي لا تتجز أ. لأن الهوية ذات، و الذات لا تعدد. بينما يمكن أن تكون لها صفات. ففي داخل كل أمة ينقسم المجتمع الى طبقات وفئات في حركية مجتمعية دائمة. هذه الحركية تجعل المجتمع كله يتفق على بعض القضايا بالإجماع. مثل صيانة الهوية و الوطن من أي عدوان خارجي، ومثل الاحتكام الى لى لهي العقل، و العمل من أجل الرقي والعدل...) (قاسم، 2013: ص26). 
وتجست عروض مسرح الكباريه السياسي في عدة عروض عربية يمكن اصطفاء بعض تلك العروض، ويأتي عرض المخرج (سمير العصفوري) (العسل عسل والبصل بصل 1986) اشارة صريحة لها امتياز ها في إنتاج هذا الاتجاه من المسرح، حيث استكملت منظومة العرض عناصر ها الفنية والجمالية الأدبية وسبل تو اصلها مع الجمهور، فنص العرض الادبي هوكو لاج شعر شعبي للثاعر (بيرم التونسي) و الذي عرف بنصوصه التي لها تماساتها مع الأوضاع الاجتماعية و السياسية، وبما اتسمت به هذه النصوص من قدر ات في القدح والهزيء لمظاهر وبنى المجتمع العربي حيث اخذ العرض لاى المخرج (سمير العصفوري) تلك السمات في مجمل عناصر الأداء (السينو غر افيا وفضاء المسرح و القاعة) تأسيساً على معطيات النص لذاته و الذي يتسم بالعادة لاى المخرج (العصفوري) بسمة الاعداد أو التوليف، حيث يأتي العرض حاملاً للسمة الملحمية مستوصياً بنية اللوحات المتو الية ليصوغ ((شكل الكباريه السياسي من خلال مقامات بيرم وتحقيق أسلوب الفوتو مونتاج photomontage مرتكزاً على دمج

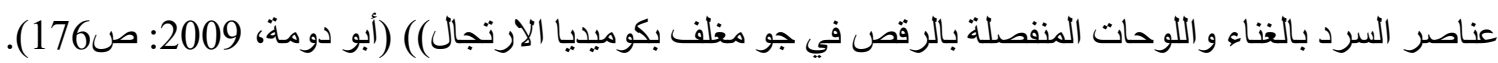

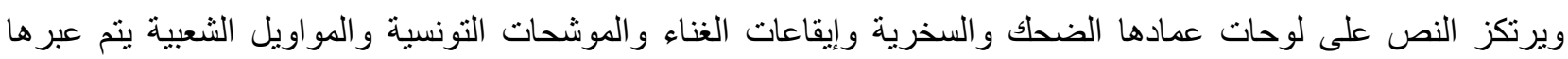
توصيل حالة الراوية الذي يتعاقب في الدخول إلى فضاءات ذات امتياز طبقي عالٍ ومنها السفارة إذ يستعرض ما يشغل الفضاء من طعام و أكلات في مجمل اللوحات، مؤشراً الى سلطة تتمثل بالمركزية الغربية معلناً عن (ان هذا زمن السندويج). وترنسم سلطة السياسة في لوحة السجن التي ترفع يافطة ساخرة (الثعب في خدمة الثرطة) ويدفع المخرج وقائع عرضه الى العصور

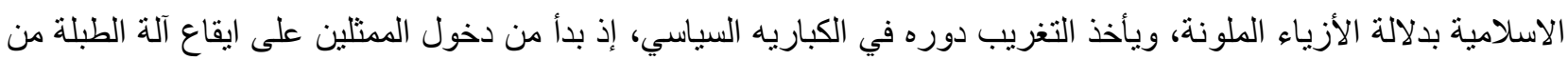
وسط الجمهور ((الأمر الذي ييلور عن حالة التمسرح اذ يدرك الجمهور ومنذ البداية إنه يشاهد عرضاً فنياً يحاوره في أوضاعه وما ير اه فما هو الا تمثيل يتطلب منه فرجة يقظة دواعية، ويعد ذلك ملمحاً أساسياً من ملامح التغريب أعيد نوظيفه في مسرح

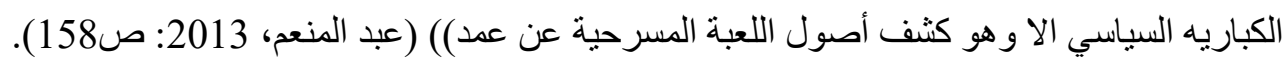
ولوحات العرض الثمانية عشر سلطت ضوءاً على واقع الحياة العربية وشؤونها الاقتصادية والاجتماعية والثقافية وأحالتها عبر دلالة الزي إلى أطو ار وحقب تاريخية مما يفتح فضاء للتغريب وخلق جسر نو اصل وقيم الحاضر، كما يحال للحو ار وبهدف إدامة كسر الإيهام الى الأزياء في تقليب صفحات التاريخ العربي الإسلامي و إسقاطاته من بعد على وقائع الازمات واهنزاز اتهات مجتمعنا المعاصر. و اتخذ المخرج العربي (عبد العزيز مخيون1943- ) من احتفالات و أعياد ومناقب و انترولوجية القرية مسرحاً له في تنوع الأشكال المسرحية الجامعة بين الأهزوجة والرقص و الزجل والثعر الهجائي في مسرحية(الصفقة) لتوفيق الحكيم لتكون شهادة

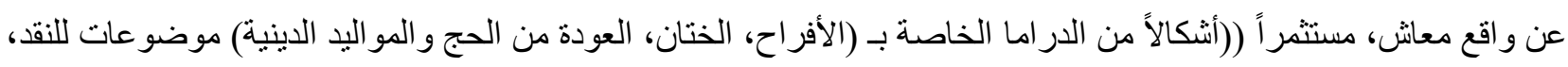
تقام الحفلة في ساحة القرية أو أمام منزل صاحب الاحتفال باجنماع الجمهور مع المنشد الديني أو المغني وفرقته او الثيخ ... وبطانته ويتسم الغناء والانشاد... في جو من التواصل الحي بين المؤدين و المستمعين عن طريق الحوار بين الطرفين أو التعليق من الجمهور على ما يسمع بالاستحسان وإظهار التأثير أو طلب إعادة المقطع من الأغنية أو جزء حكاية)(مخيون، 2015: .) وفي عرض مسرحية الكاتب (نبيل بدران 1941-2004) (باي باي لندن 1981) بأعداد لـ (عبد الحسين عبد الرضا) وإخراج التونسي (المنصف السويسي)، أخذت جماليات وأفكار مسرح الكباريه السياسي حضوراً مائزاً في منظومة العرض، اعتمد العرض اعداداً لإحدى نصوص (نبيل بدران) الكاتب الذي سخر جهده للكتابة لمسرح الكباريه السياسي، و المسرحية هو موضع 
اعداد وتللك سمة اخرى من سمات هذا النوع من المسرح الذي يقوم في الأغلب على اعداد نصوص لها محمو لاتها من الافكار

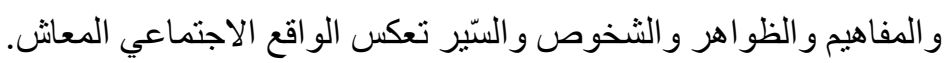
أنى عرض (باي باي لندن) منقسماً على فضائيين، هما حانة أحدى فنادق لندن وبيت (مشاري جمعة)، وكل فضاء يعكس حضور الثخصية العربية في فضاء ثقافي مثل الغرب ومعاناتها في واقع حياتي وقيمي وحضاري لله اختلافه و الواقع العربي. أتت لت

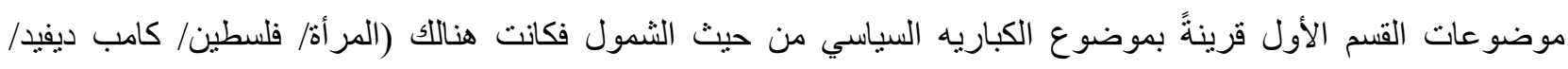
العروبة/ الاستعمار / الاستثمار / العُطلة/ الطب/ البترول/ أوبك/ أو ابك/ الصهيونية/ الروليت)، وهي تكثف عن مكونات الثخصية

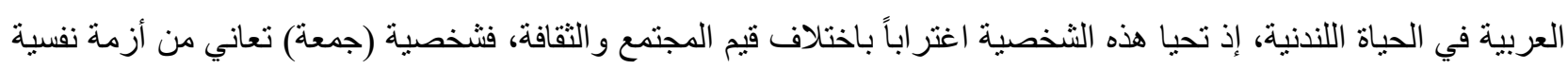
ليكون جهده التفريج عن تللك الازمة مما سبب له مواقف ومآزق جسدية ونفسية، وكذلك شخصية (نهاش) الذي تصبح موضع ابتزاز في سوق المال والاقتصاد أما القسم الثاني حمل موضوعات (تجارة الأسلحة/ طرق الأكل/ الشرب/ الأمومة/ الاتصال الجنسي/ التسوق/ الاندلس) ويتم إنقاذ جمعة بوصول زوجته و ابنته معلناً في النهاية عودته إلى بلده الأم ليودع لندن بـ (باي باي

وحمل العرض سمات الكباريه السياسي في اختزال المسافة الجمالية بين العرض والمتلقي العربي، وعزّز المخرج (السويسي) منظومة العرض بالمقطوعات الموسيقية والاغاني العربية الثعبية في مسارِ مباثر دون رموز أو استعار ات، وكذللك في إدخال الفيلم التسجيلي لـ (مدينة لندن) بمطار ها واسو اقها وشو ارعها المركزية و آثار ها الثقافية. كما شرع العرض ومنذ البداية

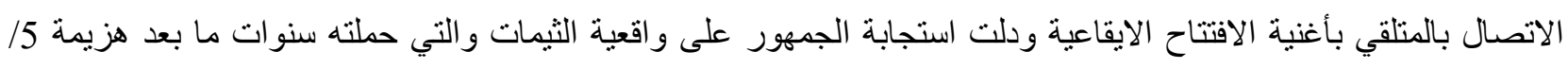

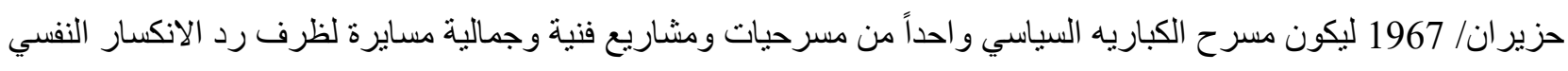
للذات العربية، فمسرح الكباريه السباسي (بطرح المشكلة المعالجة بشكل مباشر ويكثف وفي فترة زمنية محددة، كأداة الاتصال

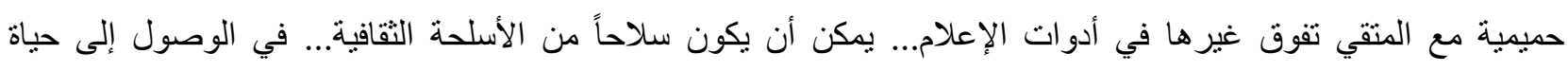

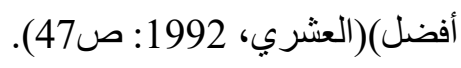
وفي المسرح السوري أتاحت رفقة الثاعر (محمد الماغوط 1934-2006) و الفنان (دريد لحّام 1934-) فرصة لإنتاج عدد من مسرحيات الكباريه السياسي ونقدها لأنظمة الهزيمة الحزيرانية كما في مسرحية (ضيعة تشرين، غربة، كاسك با وطن، شقائق النعمان) إذ حملت سمات (مسرح غنائي هجائي) وتتفيس تحولت الى خلطة من المانشيتات السياسية الساخنة، والنبرة العاطفية الميلودر امية، فالنظر الى الوطن بصفته فيمة كبرى غير مرئية، تسندعي الضحك و الهجاء وكثف الأفنعة عن شخصيات

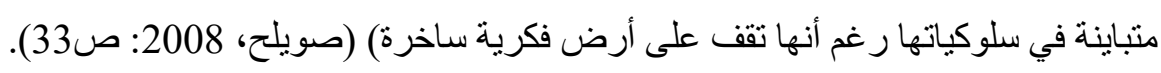
ففي عرض (كاسلك يا وطن) للمخرج (دريد لحام) يتابع المتلقي ظروف شخصية (غوّار) المعيشية والاجتماعية كونه موظف أضابير وبائع للحمص بعد الدوام، وكثف العرض مبكراً عن موجهات الكباريه السياسي، فالعرض بتناوب في أحداثه على ولى فضائيين بيت (غوّار) وزوجته (رضية) والآخر هو محطة التلفزيون، حيث تقدم المحطة وسائط عدة تخص إحدى الأقطار العربية، معتمدة وسائط عدة من (تلفزيون/ صحافة/ اخبار / غناء). ويطرح العرض حياة (غو ار) وثيمات أخرى مثل (السجن/ التربية/ الولادة/ العمل/ فساد المؤسسة) إضافة إلى عرضه الى إلى مسلسل احلام وكل ذللك دلالات اشهارية واضحة تشغل الفضاء بكليته، إضافة إلى عديد من الإعلانات للسلع الاستهلاكية. وتقوم نصوص الاشهار في المحطة التلفزيونية على السخرية من الأنظمة العربية، ففي النشرة الجوية يطرح العرض إثارة إلى سياسية 
تخص الأوضاع العربية مثل: (لبنان/ رياح من كل الجهات مع احتمال سقوط قنابل في الجنوب). وينتهي (غوار) دون (احلام) ليبيع أطفاله الثلاثة في السوق بعد حالة الاحباط في الحصول على لقمة العيش و التي يتجاوز ها مطالباً بـ (الكر امة). و عمد المخرج (دريد لحّام) الى كسر الإيهام و التفاعل مع الجمهور في التقنية الصورية التلفزيونية وحضور الراوي/ الر اوية بصفة (مذيع) و أخذ الممثلون بأداء أكثر من دور واستدعاء نصوص من الاغاني السياسية القديمة منها و المعاصرة ونصوص الأدعية الدينية. كما عمد العرض الى بعض شذرات الفنطازيا حين يحضر الأب الثهيد متسائلاً عن أحوال العرب ليجدها كما هي.

وعرف اللبناني الممثل (حسن علاء الدين1939-1975) (شوشو) و المؤلف (فارس يواكيم 1945-) و المخرج (ديوون جبارة) انتاجهم العروض مسرح الكباريه السياسي في لبنان ابتداءً من نهاية الستينيات في عرض (آخ يا بلدنا 1973) يطرح المؤلف (يو اكيم) بصيغة الإعداد المسرحي لحالة الفئة الأكثر تهميشاً مثل الثحاذين وصراعاتهم البينية للهيمنة على موارد الثوارع و الحار ات الاقتصادية، فالباثا (رئيس جمعية الثحاذين في البلا و المهر) يدخل في تصارع مع الثحّاذ (شوشو) للسيطرة وقيادة الثحاذين ليتم الإيقاع يـ (شوشو) و إرساله إلى المحكمة وليتم الحكم عليه بالإعدام إلا أنه ييريء من رئيس الدرك.

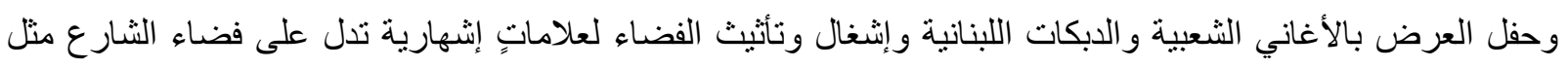

$$
\text { (إثارات المرور/صور القادة السياسيين/ رجال الاقتصاد/ الإعلام/ الصحافة). }
$$

ويسجل العرض بصر اع ثنائية (السلطة/ الثحاذين) الى حتمية انهيار قوى التسلط و الظلم، فالباشا وأفر اد الدرك هم أقل عدداً

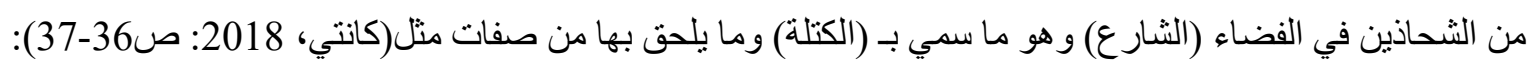
1. ان الكتلة تسعى دائماً للنمو. 2. 3. إيثار الكتلة الى الكثافة.

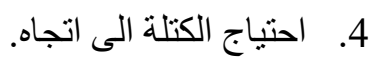
ثانياً: عر اقياً بات من الو اضح ان لمسرح الكباريه السياسي تنو عاً في الأساليب والاتجاهات و البنى الفنية، حيث يتجاور هذا النمط المسرحي مع اتجاهات عدة من المسارح التي تتخذ البعد الاتصالي مع المتلقي في إطار زمانيـ مكاني وبرسالة قصدية في إطار أسلوبي له، اذ يصعب تحديد ملامح قاطعة لهذا النمط من العروض لتنوع اساليبه في المسرح العالمي. ونجد ان الظروف السياسية والاجتماعية هي ما يتشارك بها عرض الكباريه السياسي مع الاتجاهات الأخرى من المسارح التي سبق ذكر ها. فالمسرح في مجمل اتجاهاته هو حاصل معالجات وقر اعة للوقائع الحياتية و الظروف التي انتهت اليها الذات الانسانية

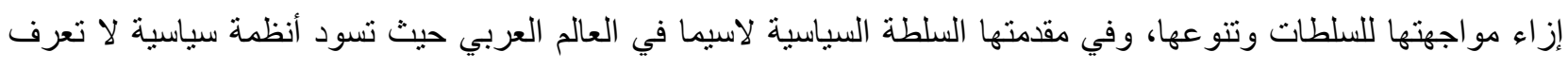
سوى وسائط العنف والاستبدادو الاستفراد في الحكم.ولعل من مسوغات ظهور عروض الكباريه السياسي في العالم العربي، هي انظمة الحكم السياسية وقو انين الحكم الآيديولوجية ذات الفكر الاحادي وهو ما اسماه الناقد (جابر عصفور ) بـ (بلاغة المقموعين) والتي اسهم في تعزيزها مجمل الفنون في مسرح وتشكيل وسرد شهدتها عقود الستينيات، وفي جملة اسالييها (ملاحظة التناقض بين القول و الفعل، المظهر و الجوهر، المعلن وغير المعلن، المنطوق و المسكوت عنه، وتمند إلى ملاحقة

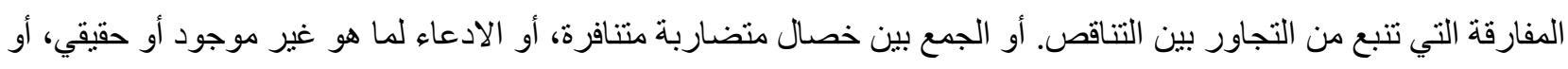


إطلاقة تسمية على ما يناقضها. ولا تتباعد هذه الملاحظة عن التوريات والإشارات والكنايات والتمثيلات التي تنطق عن

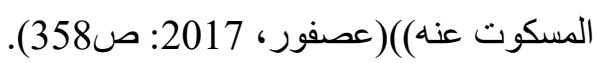

وتعد فترة الستينيات واحدة من العتبات التي شرعت بها الاتجاهات المسرحية بكل معالجاتها الا إن تلك الأنظمة وما نتج عن ممارستها من حروب ونكساتٍ وهز ائم كما في حروب (1948-1967) التي أخذت حيزاً من المعالجات في مجمل الفنون و الآداب والأفكار، وتعد المسرحية السياسية التي عرفتها المسارح العربية بعد التعرف على عروض (بيسكاتور) و(بريخت) و احدة من المعالجات التي تسيدت تللك الفترة. والمسرحية السياسية ذات أوجه متعددة في سلبها وتنوعها وما يلحق بها من بهر معالجاتٍ جعلت منها مفتوحة على أساليب عدة، ولعل عروض الكباريه السياسي يعد واحداً من تلك التتوعات التي ستكون موضوع قر اءتنا.

وللمسرح العر اقي اسهام كمي ونوعي في التعاطي مع تلك الظروف بمعالجات نصيّة وتتوعات في الاتجاهات الاخر اجية، فكانت مسرحية الخرابة (1969) لـ بوسف العاني (1927-2016) قراءة الظروف السياسية والاجتماعبة ودور الجماهير وبعض الثرائح الطفيلية/ الطبقية في رسم خارطة الوضع السياسي بعد الهزيمة. فالمسرحية ذات شكل ملحمي تقوم على اللوحات الحوارية والسجالية بين نوعين من الافكار تقدمية / رجعية وطفيلية / طبقية. تخلى الإخراج المسرحي للمسرح سامي عبد الحميد (1928-2019) مجموعة من الاشعار / لافتات / لهجات / أسماء / أعلام شخصيات عراقية سياسية وشعبية رهية

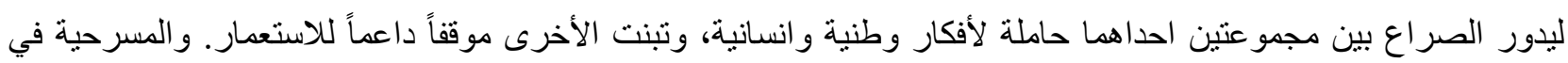

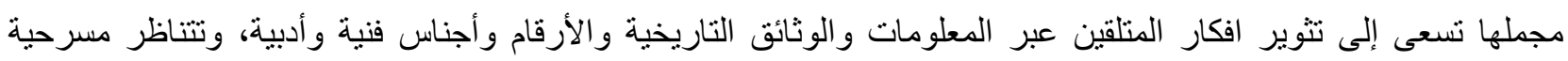

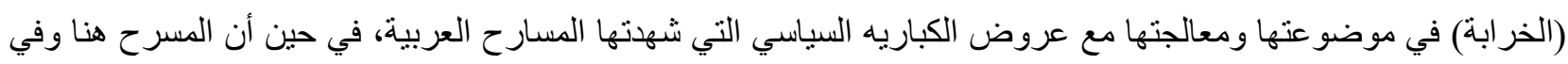
هذا النمط من الأداء (يحارب في أكثر من جبهة، حرب داخلية ضد القهر وطلباً للحرية أو الديمقر اطية. وحرب خارجية ضد

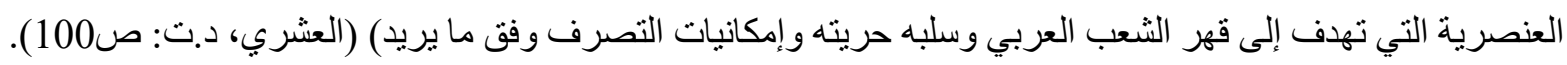
ويعد المخرج العر اقي (قاسم محمد 1936-2009) من اكثر المخرجين استجابة للتحولات السياسية التي شهدها العراق في الربع الاخير من القرن العشرين، عبر عروض لها تماساتها ومعالجاتها لأحداث، وفيها يعالج (قاسم محمد) القضايا و المشاكل التي جاءت بأثر الأزمات السياسية و الحروب، ففي السبعينيات عالج (قاسم محمد) أزمة الاحتياطات النفطية وصر اع العين الحكومة العر اقية مع شركات النفط الأجنبية في مسرحية (نفط - نفط) في عام 1973، وفيها مجمل إثارات إلى الاقتصاد و السياسة و الاستعمار و الثثورات والاحصاءات الرقمية، عبر معالجة لأزمة كانت حاضرة في الحياة العر اقية وكان لها أثرها في المستوى الهي الاقتصادي للمو اطن العر اقي. وقدم (قاسم محمد) في التسعينيات مسرحية (امريكا قارة الرعب والجوع) حيث جاء التأليف جماعياً من قبل فريق العمل الذي حمل ممثلاً سمات الثعب العر اقي بكل مكوناته وشر ائحه الاجتماعية والثقافية مو اكباً أحداث وأزمة التهديد الامريكي للعر اق إبان أزمة الكويت. و اتخذ العرض تلاقحاً واسلوب المسرح التسجيلي/ التوثيقي في مشاهد السرد وطر ح المعلومات، كما اتخذ الاخر اج سمة الجماعية وفق اسلوب المخرج (قاسم محمد) مع مجموعة الممثلين الذين تجاوز عددهم الستة عثر ممثلاً، كما اتخذ البعد التحريضي اتجاه الضر اوة الامريكية وقمعها للشعوب بعداً جماعياً عندما وقعت تحت الهيمنة الامريكية، وجاء العرض في إيقاعه المتناص مع الاتجاه التسجيلي بايقاع متواتر متوسلاً ببعض العلامات المتحولة في مستواها السيميائي والتي تركزت حول الالواح الخشبية 
بشكلها المستطيل، حيث التحول في الثكل و الوظيفة، بهدف التواصل مع المتلقي العر اقي وتعبئة امكانياته النفسية وار ادته الوطنية باتجاه العدوان الأمريكي، كما حفل العرض بأنواع مختلفة وبمقاطع متنو عة من الفو اصل للرقص الأمريكي وبعض أنواع الرقص و الغناء بهويات وطنية مختلفة لها بعدها الانثرولوجي الإنساني. و وتتوقف ثيمة عرض (ملا عبود الكرخي) على تحو لات الحياة اليومية والاقتصادية والسياسية والاجتماعية و الثقافية للشاعر (الكرخي/1861-1942) وما شهدته حياته من أحداث و اكبت مسيرته، وحمل العرض و الذي جاء بأعداد للفنان (سامي عبد الحميد 1928-2019) و إخر اج جماعي لممتلي العرض، سمات الكباريه السياسي في بنيته الفنية وسبل التو اصل مع المتلقي حيث يقوم العرض على فصلين لكل فصل اربع لوحات اتسعت لحياة الشاعر والمو اطن و الانسان (ملا عبود الكرخي) فهو شاعر له حضوره في مساحة الشعر العر اقي، وما اتسم به شعره من نقد وسخرية من المظاهر الاجتماعية والسياسية، لذلك أتت قصائده ذات نسيج درامي يزاوج بين اللوحات الثمانية للعرض سواءاً بالثعر منظوماً أو غنائياً ايقاعياً نوزع على أنماط الغناء العراقي مثل (المقام العراقي، المربعات البغدادية، الغناء العر اقي). وحملت منطقة وسط المسرح تحو لاً سيميائباً متعدد الأغر اض و الأهداف فكانت بمثابة (سوق/ حمام/ سجن/ مجرشة/ ساحة تظاهر)، و اتسعت عناصر السينوغر افيا لتشمل السايك الخلفي للمسرح وما ينعكس عليه من صورٍ وظلال ومن أجل زيادة درجة السخرية، أخذت الرؤية الإخر اجية بتوظيف الدمى للتواصل وإحالة السخرية التي اتسمت بها نصوص وحياة الكرخي. ور غم تكرار علامة (المجرشة) في أكثر من لوحة فان العرض أخذ بشمولية الكباريه السياسي في عدد المعالجات و الطروحات، فكانت هناك إثشار ات إلى (شعر ، سياسة، صحافة، مر أة، رياضة، الطلاق، الصهيونية، الوحدة العربية، اختر اعات علمية، أسرة). وتحضر عجائبية الكباريه السياسي في نهاية العرض يطل (الكرخي) من عالم الأموات إلى حياتتا المعاثة في مقاربةٍ

$$
\text { بما تحقق من أمنياته الوطنية والإنسانية. }
$$

وقدم عرض مسرحية (نديمكم هذا المساء) لمؤلفه (عادل كاظم) وبأخر اج (محسن العزاوي) تاريخاً طويلاً لحقبة الاحتلال العثماني و الانكليزي عبر سرديات وحكايات ومشاهد لشخصية الممثل (حمادي الهِبش) وهي شخصية حقيقية اعنادت عليها بعض ملاهي وكباريهات بغداد، فالممثل (جعفر لقلق زاده) بتقديمه لهذه الثخصية أشاع تقديم سيكتشات غنائية و إثار ات ومقاطع من الشعر الشعبي العر اقي ولما يشبه أداء الفرجة وبتقنية ممثلةٍ بـ (الميتا مسرح) فـ (حمادي الهبش) يروي لنا وعبر معايشته للأحداث تلك الحقبة وظروفها الاجتماعية والسياسية والاقتصادية ونقده الساخر السياسية بتقديم بعض المربعات البغدادية و القصائد الثعبية و أفعال التقليد لبعض الثخصيات. و السمة الغالبة على تقديم (جعفر لقلق زاده) هي مشاهد من نوع الكوميديا (الفارس) كما هو في المنتديات الليلية.

وشهدت المسرحية تحو لات في إثغال الفضاء وسينو غر افيته فكان هناللك فضاء السمسارة (ريجينا) وقدرتها على التحكم في صنع القرار السياسي، فكان المكان يؤثث وفق علامات (ريجينا)، كما حمل العرض علامات التظاهر التي شهدتها منطقة (الحيدر خانة) بعد مقتل الأخرس من قبل قوى الاستعمار الإنكليزي، ودفع الإخر اج الى منح (جعفر لقلى زاده) سمة الجدّه حيث

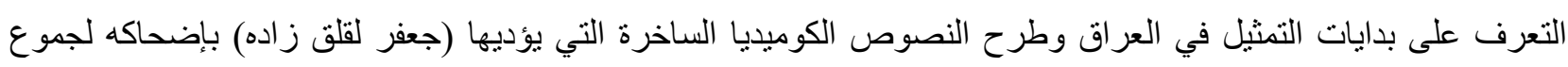
الشعب بو اسطة التقليد.

و اعنمد العرض أسلوب التغريب البريختي حيث عبر الممثلان المعاصر ان بهدف منح العرض سمة اللوحات وتنو عاتها من جهة، ومن جهة اخرى دفع الكثير من المشاهد للحياة التي عاشها (جعفر لقلق زاده). 
ما أسفر عنه الإطار النظري

1. قارة المسر ح للاستجابة للظروف الحياتية وطرق معالجتها.

2. بهدف إحداث التأثير على المتلقي يعتمد عرض الكباريه السياسي منظومة وشبكة من النصوص والأجناس والوسائط و التقنيات.

3. التناصات بين مسرح الكباريه السياسي وريادات المسرح السياسي الأولى (بسكاتور، بريخت) من حيث كسر الإيهام أو كثف اللعبة المسرحية.

4. ترحيل النصوص المسرحية إلى فضاء المسرح بو اسطة الإعداد وانتقاء بنية ذات سمة تو اصلية مؤثرة. 5. يشهد فضاء العرض المسرحي الكباريه السياسي تحو لات سيميائية ملحوظة ومتلاحقة للعلامات بغية التأثير على المتلقي. 6. اعنماد المخرج في الكباريه السياسي فضاءً احادياً.

7.

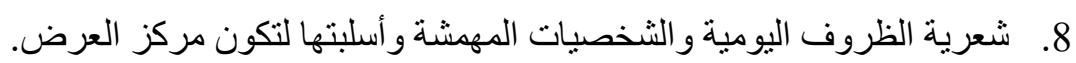
9. انفتاح جماليات مسرح الكباريه السياسي على أساليب وتيار ات إخر اجية متعددة قصد التأثثر و التحريض إز اء المتلقي. الفصل الثالث الإطار الاجرائي اولاً: مجتمع البحث الاجثان

\begin{tabular}{|c|c|c|c|c|}
\hline سنة العرض & تأليف & إخراج & اسم المسرحية & $ت$ \\
\hline 2014 & كريم شغيدل & كاظم النصار & احلام كارتون & .1 \\
\hline 2015 & د. جو اد الاسدي & كاظم النصار & نساء في الحرب & .2 \\
\hline 2016 & علي عبد النبي الزيدي & كاظم النصار & و عاثو ا عيشة سعيدة & .3 \\
\hline 2017 & كاظم النصار & كاظم النصار & سينما & .4 \\
\hline
\end{tabular}

ثانياً: عينة البحث

اعتمدت الطريقة القصدية وفقاً للمبرر ات النالية:1. إن هذه العروض ممثلة لمشكلة البحث و أهميته و هدفه. 2. تضمنت هذه العروض مادة لها الحظ الأوفر في احتو ائها على جماليات مسرح الكباريه السياسي. 3. غطت هذه العروض المختارة الحقبة الزمنية للبحث. 4. مشاهدة الباحثة للعروض على خشبة المسرح الوطني. وبناء على ما تقدم كانت عينة البحث المختارة عرضين وكما هو مبني في الجدول الآتي:

\begin{tabular}{|c|c|c|c|c|}
\hline سنة العرض & تأليف & اخراج & اسم المسرحية & $ت$ \\
\hline 2014 & كريم شغيدل & كاظم النصار & احلام كارتون & .1 \\
\hline 2017 & كاظم النصار & كاظم النصـار & سينما & .2 \\
\hline
\end{tabular}


اعتمدت المنهج الوصفي (التحليلي) في تحليل العينة وفقاً لما تمليه عليها طبيعة البحث.

رابعاً: اداة البحث

اعتمدت على ما تمت الإشارة إليه في الإطار النظري من مؤشرات لتحليل العينية المنتقاة.

خامساً: تحليل العينات

(1) العينة رقم

(أحلام كارتون)

تأليف: كريم شغذل

إخراج: كاظم النصار

سنة العرض: 2014

ينزع عرض (أحلام كارتون) شأنه وعروض مسرح الكباريه السياسي اتجاه الواقع اليومي المعاش من قبل شرائح المجتمع بصور السخرية و الهزيء و الكاريكاتيرية والثكوى المرة، فالأحداث في منون المسرح الكباريه السياسي نأتي سابقة أو مو اكبة لإنتاج العرض المسرحي ذاته. ويبسط عرض (أحلام كارتون) ثنائية الواقع/ الحلم، والحاضر/ الماضي، واليأس/ الأمل، فالثخصيات الأربعة ممثلة بـ (المثقف / الجندي/ المغنية/ رجل الدين) جيل سابق للعصف الذي شهدته الساحة العر اقية بعد عام 2003، فهم من أجيال سابقة للحدث هذا إلا إنهم في حالة خذلان ومر اوحة بين الماضي بكل مأساته و ألمعيته وبين الواقع المضبب لإبـ ليتم إنتاجاً عابراً للحياة المعانشة وسلطاتها القائمة. والثخصيات هنا في مكوناتها الذاتية نمذجة لشخوص منتقاة من المجتمع العر اقي عبر عقود طويلة تطرح هنا كذكريات آفلة ومنطفأة، لتكون من بعد أنماطاً لشخوص أو أمثولة لذوات لذا أتت دون اسماء حاملة انماطها الحياتية في إعدادها لإنتاج عدسة مكبرة للمجتمع العر اقي جامعاً وبشمولية عالية شر ائح وطبقات المجتمع، وتأخذ الثخوص الأربعة أبعادها ومكوناتها من ذخيرة الذكريات أو التاريخ الذاتي والموضوعي القريب. فكانت لكل واحدة منها سردياتها/ ذكرياتها يتم بها وعبر ها طرح محنتها التي تصل حد الثكوى، فالجندي له سرديته في مواجهة العدو وهو على خط النار وظروف ثكنته العسكرية وتسرد ذكريات الجندي على تللك الاحداث الماضية دون غير ها، فهو وجد ليكون مقاتلاً ومستجيباً للأو امر و القو انين التي تصدر ها المؤسسة العسكرية (سلوكاً، لغة، إثار ات، ألفاظ وحركات). ويأخذ تقديم شخصية المثقف تنميطاً في تو اصله مع الثخوص الثلاثة، فهو أسير معجم الحذلقة اللفظية والاستعر اض الثقافي وعبار ات التفلسف والترميز، فليس له فرصة في الوجود في مجتمع مأزوم بكل مشاكله الحياتية عامة، وذللك مبرر لرجوعه صوب متحف ذكرياته السابقة حين كان الكتاب ملازماً للعقل و القر اعة فعل حياتي يومي. وتستدعي شخصية المطربة/ المغنية ايامها الذهبية في امكنة اللهو والمتعة لتتساءل بعد اشو اط التحريم والخوف من الغناء، تتساءل عن نماذج (الافندية بإنشارة (وينهم) فكانت سلوتها شذرات ومقطو عات غنائية ايام مجدها الفني في عقود الخمسينيات، اما رجل الدين فإنه في حالة شكوى إزاء الاضطهاد الذي واجهته بها السلطات السياسية السابقة ليتم سرد حكاية والده اتجاه تلك السلطات شأنه و الثخوص الثثلاثة معايثاً حالة الو اقع وكيف انتهت بيوت العبادة إلى أمكنة للتفخيخ وقتل عوام الناس بالأسواق

والشوارع وكل الأمكنة المأهو لة. وحمل الحوار لمجمل الثخوص الأربعة سمات المفارقة والسخرية والغروتسك باختز الاته البرقية أثر تتاوب هؤلاء الثخوص على تقديم ذو اتهم وخز انة ذكرياتهم واحباطاتهم و أوجاعهم في لحظتهم المعاثـة. 
ويحضر العنوان صريحاً في نهاية المسرحية إذ يتم اجهاض الأحلام الاربعة للشخوص، فوصولهم للمطار لغرض المغادرة| السفر وهو موضوع حلمه بالمغادرة، يتم إيقافهم من قبل السلطات بحجة وجود خلل فني بالطائرة ويأخذ المكان سيميائيته من

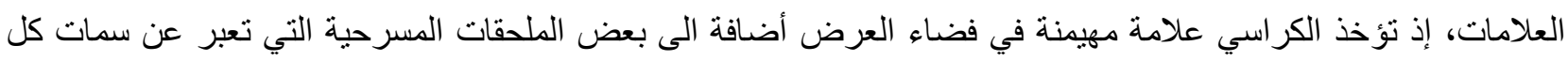
شخصية المسبحة/ الكتاب/ الثشال/ البيرية) كما يتأسس المكان بشحنات نفسية واجتماعية وسلطوية وفق توالي المشاهد وتقليب وسرد الأحلام وتو الي تقويضها ايضاً، فكان المكان حاضنة لتلك التنوعات وليصير من بعد العودة أو التدوير إلى حيث عنبة البداية بفعل دفع الحقائب الأربع إثارة إلى توقف الطير ان، وتلانك هي بداية المسرحية أيضاً. وأخذ عرض (أحلام كارنون) سمات التقشف والاختز ال السمة العامة والسائدة في عروض مسرح الكباريه السياسي ممثلاً بعلامة الملابس، فكان لها اثنار اتها الى الثخصية ونمطيتها طوال العرض مع بعض بعض العلامات الأخرى مثل العباءة الواقية و النجادة، ولعلامة الملابس دور ها المزدوج في التعبير عن انشطار الثخصيات وازدواجيتها القيمية أيضاً فلكل ذات هنا في حالة انشطار وتمزق ذاتي بين الانتماء الى الواقع وتعزيز الحلم او بين الافتراض / الطيران وسلطة الواقع، حيث تتضح سمات ومكونات الثخصية عبر الملبس وملحقاته الاخرى، وانشطار الثخصيات يبدو على وجهنين، إحداهما قيمية والأخرى فنية، فالثخوص أو الذوات هنا لها منظومتها السلوكية في أوقات الأزمات و الأحداث الكبرى، لذا رشحت من تلك الذوات قيم خارج نمط الصفة الحياتية التي تحملها وتعاكس أيضاً مكوناتها من أنظمة السلوك اليومي، اما الوجهة الثانية فهي في تعدد أو تنصيف الثخصبة إلى حيث الادوار وأدائها هنا بلحظتي الماضي و الحاضر بأسلوب يكثف عن الفجوة والفر اغ بين الحدين ما يخلق سمة

$$
\text { للسخرية و المفارقة و الحنين إلى الماضي. }
$$

وتتأسس شمولية مسرحية السياسي في منظومة العلامات الإشهارية التي تحيط بالمكان (المطار) سواء اللفظية منها و الصورية و هي سمة شمولية لمسرح و عروض الكباريه السياسي، فكانت هناك إثنارات مثل (قناة العربية/ اتفاقية سايكس بيكو/ الكوته/ الأذان/ التفخيخ/ الأغاني/ الثعر...). الا ان سرد الثخصيات له نمذجته وفق انماطها الحياتية ليكون هنالك أربع سرديات بكل دلالتها ومعجمها وموحياتها ومسارها الحياتي، فكان لذلك إنتاج سمة بليفونية من الثخوص، وهو مدعاة أخرى لفتح فضاء الكاريكاتيرية اثر الفو ارق و الفو اصل بين تجارب الثخوص الأربعة، وتأكيد على فعل (طير / طبر) مبرر لتتوع الفضاءات بسمة الفنطازية، فالطائرة في رحلتها الى (هونك كونك) تتوجه بفعل الخطف المفترض اتجاه افغانستان ما يطرح نمطاً علاماتياً ساخر اً

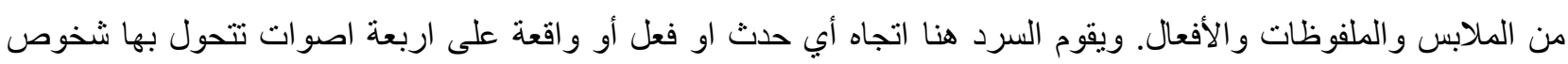

$$
\text { ثلاثة الى (راوين لهم) في تو اصل مع (راوي للحدث). }
$$

وتأخذ الاغاني العر اقية بالكثف عن الانتماء الذاتي والجمعي لدى الثخصيات الأربعة، إذ يذهب العرض الى إنتاج نصوص غنائية عرفتها عقود الاربعينيات العر اقية وصولاً الى الستينيات وما يلحقها من ايقاعات للرقص الثعبي العر اقي ورقصة الهجع) اضافة الى الاغاني الحماسية والتعبوية التي كانت حاضرة في مسامع وترديدات السلطة الثقافية أبان هزيمة حزيران 1967 ما أدى إلى رسم صور بين الماضي و الحاضر بطرقٍ هزلية وكوميدية ما يعني تكرار انتاج الهزائم العربية على مستويات الثخوص وله و الثر ائح و الطبقات الاجتماعية والثقافية و السلطات الحاكمة، و التي تحضر بالعرض هنا مر اقبة للأحداث ومعاقبة للثخوص حين تصادر حلم الطير ان، إذ سنظل الثخوص مناشدة لمر آتها الذاتية بدلالة مكانية (وين... وين). 
يتوسل المؤلف و المخرج (كاظم النصار) ثانيةً في عرضه هذا بتقنية الفنطازيا وكما في عرضه السابق (العينة الأولى) بين الواقعة والخيال أو الغريب من الأحداث، ويبدو ذللك في طبيعة وسيمياء المكان الذي تدور فيه الاحداث وهو المقبرة، فالأموات الاربعة (السائق، الصحفية، الثاعر، الجنر ال) تتفاوت مدة إقامتهم في المقبرة بين الثناثين سنة والتسع سنوات، ما يعني اختلاف سبب وظروف رحيلهم أو وفاتهم. فكانت شخصية (الجنر ال و الثاعر) من أقدم الأموات في المقبرة لبلتحق بهم تباعاً (الصحفية وسائق سبارة الاجرة) ويكون ذلك بعد ما سمي بـ (الزلزال) أو عام 2003 لنشهـ وبروح الظر افة ثمة تجادلات وحجاجاً بين الجيلين وظروف تعاطيهم مع الو اقع الزلزالي الجديد أثر انقطاع الجيل الأول الجنرال/ الثاعر عن الاحداث، إضافة الى ما يكثفه

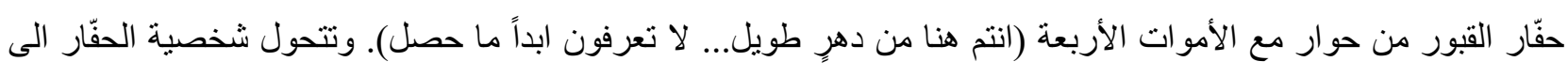
بورنريت لتاريخ المأساة العر اقية ونص يسجل بداية تلك المأساة التي بدأت من عام 1980، إذ يدون الحفار ذلك بأنشارنه (1980 حفرت أول قبر في حياتي وآخر قبر كان 2007). وشأن نصوص الفنطازيا التي حملتها الأجناس الأدبية والفنية الأخرى ينشد عرض مسر حرح الكباريه إلى توسيع فضاءات الأحداث و إمكنتها في فضاء المسرح، فهنالك الحكايات و النوادر و القصص و الامثال و المأثورات الثعبية ليلحق بها سيرة حياة تخص كل شخصية سواء في حياتها اليومية ونشأتها وادوار ها الحياتية وأسباب وظروف رحيلها الى العالم الآخر، وهي إثنارة هنا الى ولى

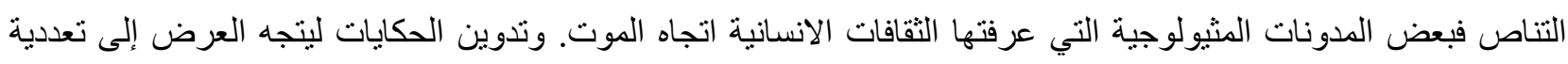
الأمكنة و الفضاءات وسماتها الثقافية بين (جبهة القتال، الجنرال، الدهس، الاغتبال، التغيير، معجم السائق، ملفوظات الثاعر). و اخذ المؤلف و المخرج (كاظم النصار) هنا إحالة و إثارة إلى سمات اللامعقول وظروفه السائدة التي تحياها الذات العر اقية طو ال أربعة عقود من الحروب، ورغم سعي الثخوص الأربعة وتطلعها الى الخلاص أو المخلص من قبضة السلطة في الحياة الدنيا تظل ثمة سلطة ملاحقة لها في حياة القبر تمثلها سلطة حفار القبور وخلفها سلطة صاحب المقبرة وجشعه بإضافة أعداد من الموتى ونى

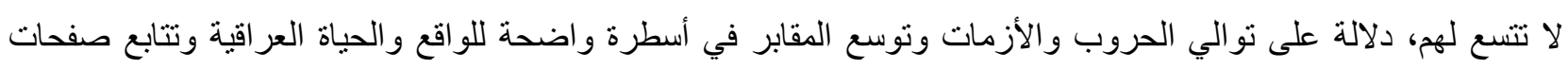

الحروب وتنو عها بين الداخل و الخارج.

وسعى العرض كما هو شأن المخرج (كاظم النصار) الى تفعيل الفاصلة بين صور الو اقع والخيال و المدونات اليومية وبنصوص معاشة وهي نصوص إثهارية نعنى بترويج بعض السلع، فنصوص الموت و القتل لها نصوصها الإشهارية مثل الإشهار عن العطور الهندية/ وأنواع القبور... إضافة إلى اشهار يخص مساحيق الغسيل في مجاورة سيميائية واضحة تبعث على السخرية

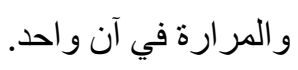

وتأخذ الفنطزة أبعادها في التو اصل مع الحياة بواسطة الخطابات السياسية، حيث تتوفر ذات الخطابات ونصيتها في و اقع المقبرة التي تحمل أيضاً دعوات إلى الانتخابات و عرض بعرادها فئ المرشحين من الموتى وجماهير هم عبر منصات الاتصال، فهنالك أي المقبرة تعرض الثخصيات الأربعة بر امجها ورؤيتها لحل الازمة السياسية العر اقية بعد الزلز ال، وما يحدث من احتدامات ومكائد وتنازعات وتناز لات على المناصب والحقائب الوزارية السيادية وهو نظير الحياة الواقع ليفتح العرض تجسيراً بين الأموات و الأحياء و هي و احدة من دلائل الفنطازية في رسم صورة تجمع النقيضين. 
وسدد النص إثـارة ساخرة الى اثكالية الفجوات الثقافية بين الثقافة الشعبية ممثلة بشخصية السائق والثقافة النخبوية التي تقترن بالثشاعر ، وما بينهما من مساحة للنظر الى الأشياء و أفعال الحياة وهي فرصة در امية عمادها المفارقة هدف إليها عرض الكباريه السياسي هنا، فدلالة المر آب لاى السائق هي ذاتها من خلال الإحالة الر امزة الى المرآب لدى الثاعر لتفتح فجوة تعبيرية بين سبل

ووسائط التو اصل بين وجهتين حياتيتين وقاموسها اليومي.

و اكتفى العرض بأحادية الفضاء وتتو عت بعض العلامات فكانت المقبرة الساحة الرئيسة للأحداث و الاسترجاعات والاستبدالات السيميائية معبرة عن سمة مكانية ذات ثنائية منباينة (هنا)/ (الآن) أو (الهنا)/ الهناك) حسب مسار الاحداث وتتصيفها بين حياة القبور و الحياة العامة المعاثة او الماضي و الحاضر. فليس ما يشغل فضاء المسرح لدى المخرج (كاظم النصار) و وعروضه في الكباريه السياسي سوى علامة واحدة تبسط حضور ها و أداءها وتحو لاتها السيميائية، فكلما كانت علامة الكر اسي في العينة الاولى (احلام كارتون) أتت المقبرة متمركزة بـ الفضاء بكتل عمودية و افقية ترمز الى القبور وما يلحق بها من افعال و علامات سيميائية حين تنشط فعالية التحول لتكون تلك الكتل (ساتر قتال/ منصة/ سيار / موقع اعلاني...). كما أخذ التحول السيميائي أيضاً أبعاده في الملحقات المسرحية وماتختزله من حضور للوحدة الزمكانية ويؤشر ذللك بقص وسرديات وذكريات وتجارب كل شخصية، وفيها تستدعي علامة نوقف الصفة الثخصية وأبعادها الاجنماعية من ملبس واعتداد كل شخصية بسجلها الحياتي ليكون سبباً لاحتفاظها بعلاماتها من تللك الازياء إحالة الى الواقع الثقافي والاجتماعي والاقتصادي الذي أنتج تلك الأزمات، واستمراراً

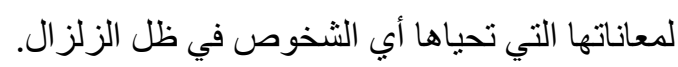
ويعزز المؤلف / المخرج كاظم النصار فنطازية العرض بتناصاته بنصوص حياتية تمثل ملفوظات وامثالاً ونعوتاً و استعار ات نتاج الو اقع الحياتي و التواصل بين الأفراد و أيقونات لفظية لوصف الاحداث لنشهح القاباً وكنايات لأصحاب المهن

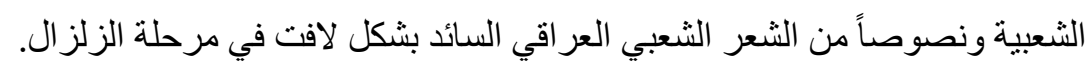
وذهبت النصوص الإشهارية الثناثة الى اللعب اللفظي و الإيحاء بحالة التغريب بين الواقع والصنعة الفنية. فنخوص المقبرة نظل في التفات وحنين إلى الحياة، عطفاً على معاناة أفرادها و إثنارة إلى استمرار ذات المعاناة التي حملتها وهي على ولى الإه سطح الحياة. وحفلت لغة التو اصل و الجدل و المحاججة بعلامات بينية واصلة بين المقبرة وفعل الحياة ما وسع من تتوع مواردها الدلالية وأخذها بأكثر من مرجع لغوي لتكون اللغة ذات انزياح و الاستعمال القار والمستقر عبر ترديدات الثخوص ومحاولة اللعب بالمفردات والدلالات وفق معجم كل شخصية ومرجعها الثقافي، ومن هنا فان المنظومة اللغوية في عروض الكباريه

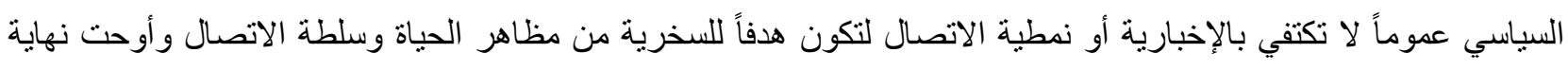
العرض بحركات الدخان باستمرارية الحفر إثارة زمكانية تخص الحياة العراقية و أزماتها، فالذات في النص هي ذائ ذات حياتية

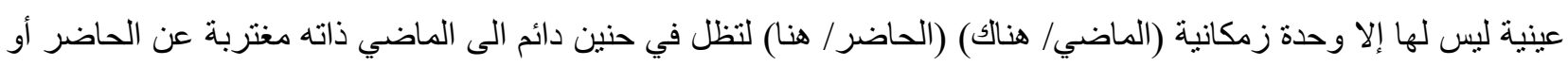
الو اقع وتتطلع الى المستقبل، فالثخوص لا تمنللك أي اشارة الى المستقبل لتظل تحت سلطة الدفاع عن ماضيها وحاضر ها بكل هل تهافته الحياتي ليكون المستقبل مجهو لاً معبر اً عن بشاعة معطيات حياتها المعاثة. 
الفصل الرابع

نتائج البحث

اولاً: النتائج

1. تشرع ملامح عرض الكباريه السياسي لاى المخرج كاظم النصار بدءً من العنوان أو مايسمى بعتبات النص حيث إنزياح الدلالات اللغوية مثل (أحلام كارتون، سينما) وما تفتحه من أفنٍ لدى المتلقي.

2. ملت عروض النصّار معالجات لوقائع يومية اتسمت بنمط الغروتسك حيث الافراح والاحزان وتناوبهما داخل منن

العرض.

3. عني الاداء التمثيلي بانتاج اللغة الثعبية والتوسل بالارتجال، حيث الابتعاد عن التقصص وفتح خط التواصل مع المتلقي. 4. بنية عرض الكباريه السياسي لدى النصار تتأسس على مركزية المفارقة بين الافتتاح والاختتام ما يؤدي الى أفق الدهشة

و السخرية.

5. الخطاب الاشهاري عنصر اً مساهماً في انتاج عرض الكباريه السياسي لاى النصّّار باستد عائه ماهو يومي وسائد ومألوف.

6. التقثف في عناصر منظومة السينو غر افيا واعتماد عناصر ذات سمة وفعالية في اشغالها لفضاء العرض.

7. اعنماد السمات العجائبية في تخطي الثخصيات لو اقعها الآني و اعتمادها سُبلاً للخلاص من الو اقع.

8. يتهيكل عرض الكباريه السياسي لاى النصار على ثنائية الو اقع / الحلم ليقوم على بنية التدوير و الرجوع الى فع الابتداء.

9. جاء تعدد الثخصيات و ابعادها التقليدية والنمطية معززاً للالالات البليفونية داخل فضاء عرض الكباريه السياسي. 10. استجابة عرض الكباريه السياسي لاى النصار لسلطة المكان وقيمته الثابتة وتحو لاته السيميائية بين التجسيدية و الذهنية. 11. اهتمام مسرح الكباريه السياسي بصيغ التلقي و التوصيل بو سائل أقرب إلى الذات دون ابعاد تأويلية وشفرات لئه غامضئ.

ثانياً: الاستنتاجات

1. جدل العرض المسرحي مع ذاته في انتاج مستوى من التجريب وفق وقائع وأحداث الحياة ذاتها.

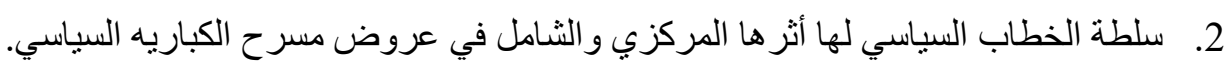
3. تخطي عروض مسرح الكباريه السياسي أنماط التصنيف للأجناس الفنية والجمالية واعتماده شبكة من النصوص الجمالية و المهمشة الفنية وغير الفنية. 4. تأتي عروض مسرح الكباريه السياسي متفحصة لوقائع الحياة الانسانية بعيد الازمات و الحروب و النكسات. 5. التوسل بنصوص ذات منحى كو ميدي وكر كاتيري ساخر وذلك بهذف الإثارة و التنأثير و المحاججة.

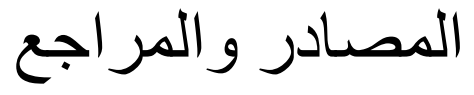

[1] احمد العشري، المسرحية السياسية في الوطن العربي، القاهرة: دار المعارف، 1992.

[2] ادوارد الخراط، الحسّاسية الجديدة. مقالات في الظاهرة القصصية، بيروت: دار الآداب، ط1، 1993. [3] أريك بينتلي، نظرية المسرح الحديث، تر : يوسف عبد المسيح ثروت، بغداد: دار الحرية للطباعة، 1975. 
[4] أم الزين بن شيخة المسكيني، الفن يخرج عن طوره أو جماليات الرائع من كانط الى دريدا، تونس: دار المعرفة للنشر، .2005

[5] امين المميز، بغداد كما عرفتها شذرات من ذكريات، بيروت: مكتبة الحضارات، ط1، 2010. [6] ايريكا فيشر - ليتشه: جماليات الأداء. نظريات في علم جمال العرض، تر وتقديم: مروة مهدي، ط1، القاهرة: المركز القومي للترجمة، 2012.

[7] بيرنار كاتولا، الاشهار والمجتمع، تر: سعيد بنكراد، اللاذقية: دار الحوار للنشر والتوزيع، ط1، 2012. [8] جابر عصفور، قصيدة الرفض. قراءة في شعر أمل دنقل، القاهرة: الهيئة المصرية العامة للكتاب، 2017. [9] جريج جايسكام، الفيديو والسينما على خشبة المسرح، تر : د. محمود كامل، القاهرة: الهيئة العامة للكتاب، 2011.

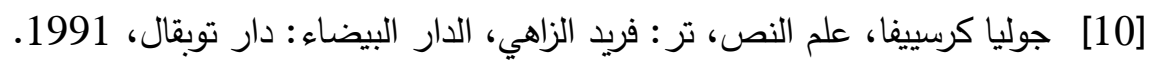
[11] ] جوليان هلتون، نظرية العرض الدسرحي، تر : نهاد صليحة، الثشارقة: دار هلا للنشر والتوزيع، د.ت.

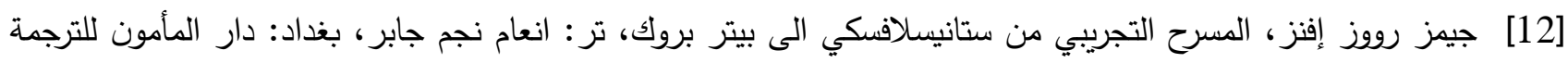
والنشر ، 2007.

خليل صويلح، محمد الماغوط. سنون الضجر، دمشق: الأمانة العامة لاحتفالية دمشق عاصمة الثقافة العربية، 2008.

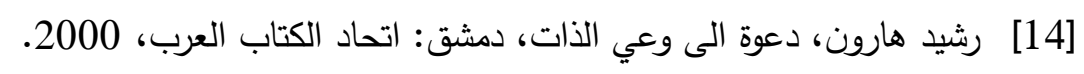

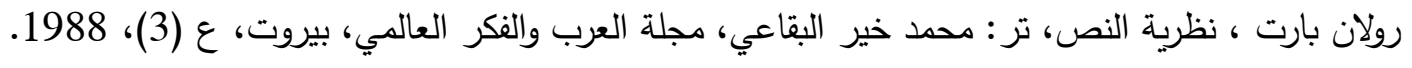

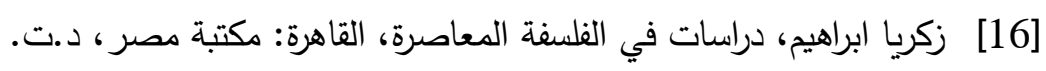

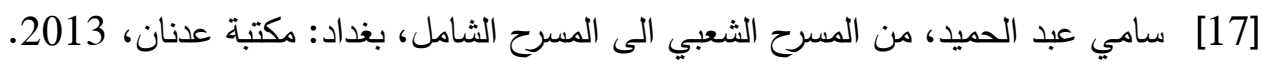
[18] سوزان بنيت، جمهور المسرح نحو نظرية في الإنتاج والتلقي المسرحيين، تر : سامح فكري، القاهرة: مطابع المجلس الأعلى لفئل لـآثار ، 1995.

شكري عزيز ماضي، انعكاس هزيمة حزيران على الرواية العربية، بيروت: المؤسسة العربية للدراسات والنشر، ط1، 1978.

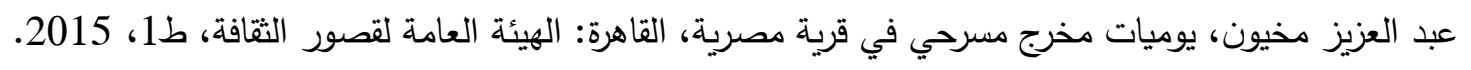
[20] عبد اللطيف عادل، بلاغة الإقناع في المناظرة، بغداد: مكتبة عدنان، 2013. [21]

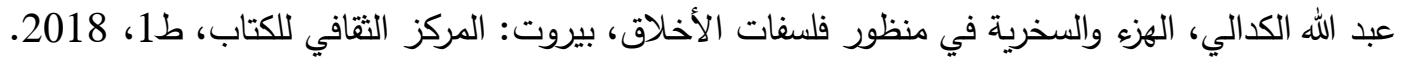
عبد الهادي بن ظافر الثمري، استراتيجية الخطاب. مقاربة لغوية تداولية، ط1، بيروت: دار الكتاب الجديد المتحدة،

علي عبود المحمداوي، الاثكالية السياسية للحداثة. من فلسفة الذات الى فلسفة التواصل، بغداد: مكتبة عدنان، 2015. [24]

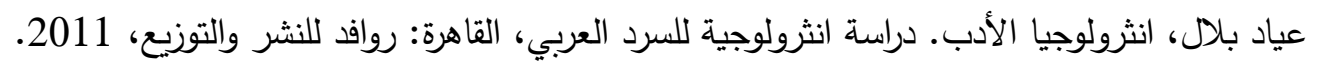
[25] [26] مارفن كارلسون، فن الاداء. مقدمة نقدية، تر د. منى سلامة، ط1، القاهرة: دار هلا للنشر والتوزيع، 2000. مارك جيمينيز، مالجمالية، تر : د. شربل داغر ، ط1، بيروت: المنظمة العربية للترجمة، 2009. 
[28] مجموعة من النقاد الروس، الثقافة وعلم الثقافة في القرن العشرين، تر : هدى علي عبد، بغداد: دار المأمون للنشر والتوزيع،

[30] [ محمد أبو دومة، تحولات المشهد المسرحي الممثل والمخرج، القاهرة: الهيئة المصرية العامة للكتاب، 2009.

[31] [محد عبد المنعم، المخرج في مسرح الكباريه السياسي، القاهرة: الهيئة المصرية العامة للكتاب، 2013.

ناتالي بييفي- غروس، مدخل الى التتاص، تر : عبد الحميد بورايو، دمثق: دار نينوى للدراسات والنشر والتوزيع، 2012.

الهوية وقضاياها في الوعي العربي المعاصر، تحرير وتقديم: رياض زكي قاسم، بيروت: مركز دراسات الوحدة العربية، ط1،

3الياس كانتي، الجماهير والسلطة، تر : محمد ابو رحمة، القاهرة: المركز القومي للترجمة، ط1، 2018.

\section{References}

[1] Ahmed Al-Ashry, The Political Play in the Arab World, Cairo: Dar Al-Ma'arif, 1992.

[2] Edward Al-Kharrat, the new sensitivity. Articles on the Anecdotal Phenomenon, Beirut: Dar Al-Adab, 1st Edition, 1993.

[3] Arik Bentley, Modern Theater Theory, Tr: Yusef Abd al-Masih Tharwat, Baghdad: Freedom House for Printing, 1975.

[4] Umm Al-Zain Bin Sheikha Al-Maskini, Art is out of phase or wonderful aesthetics from Kant to Derrida, Tunisia: House of Knowledge for Publishing, 2005.

[5] Amin Al-Mumayaz, Baghdad as I knew it Fragments of Memories, Beirut: The Library of Civilizations, 1st Edition, 2010.

[6] Erica Fischer-Leche: Aesthetics of Performance. Theories in the science of the beauty of presentation, presented and presented by: Marwa Mahdi, 1st Edition, Cairo: The National Center for Translation, 2012.

[7] Bernard Katula, Publicity and Society, Tr: Said Pinkrad, Lattakia: Dar Al-Hiwar for Publishing and Distribution, 1st Edition, 2012.

[8] Jaber Asfour, a poem of rejection. Reading in the poetry of Amal Dunqul, Cairo: The Egyptian General Book Authority, 2017.

[9] Gregg Gaiscam, video and cinema on stage, Tr: Dr. Mahmoud Kamel, Cairo: General Book Authority, 2011.

[10] Julia Kricyeva, Text Science, Tr: Farid Ezzahi, Casablanca: Dar Toubkal, 1991. 
[11] Julian Hilton, The Theory of Theatrical Performance, TR: Nihad Saliha, Sharjah: Dar Hala for Publishing and Distribution, $d$.

[12] James Rose Evans, Experimental Theater from Stanislavsky to Peter Brook, Tr: Anam Najm Jaber, Baghdad: Al-Ma'mun House for Translation and Publishing, 2007.

[13] Khalil Sweileh and Muhammad Al-Maghout. Years of Boredom, Damascus: General Secretariat of the Damascus Celebration, Capital of Arab Culture, 2008.

[14] Rashid Haroun, An Invitation to Self-Awareness, Damascus: Arab Writers Union, 2000.

[15] Roland Barthes, Text Theory, TR: Muhammad Khair al-Buqai, Journal of the Arab and International Thought, Beirut, P (3), 1988.

[16] Zakaria Ibrahim, Studies in Contemporary Philosophy, Cairo: Library of Egypt, d.

[17] Sami Abdul Hamid, From the Popular Theater to the Mass Theater, Baghdad: Adnan Library, 2013.

[18] Suzan Bennett, The Audience of Theater Towards a Theory of Theatrical Production and Receptions, Tr: Sameh Fikry, Cairo: Supreme Council of Antiquities Press, 1995.

[19] Shukri Aziz Madi, The Reflection of the June Defeat on the Arabic Novel, Beirut: The Arab Foundation for Studies and Publishing, 1st Edition, 1978.

[20] Abdel Aziz Makhion, Diary of a theater director in an Egyptian village, Cairo: The General Authority for Cultural Palaces, 1st Edition, 2015.

[21] Abdul Latif Adel, The Rhetoric of Persuasion in the Debate, Baghdad: Adnan Library, 2013.

[22] Abdullah Al-Kadali, Mockery and Sarcasm in the Perspective of Philosophies of Ethics, Beirut: The Cultural Center for Book, 1st Edition, 2018.

[23] Abdul Hadi bin Dhafer Al-Shammari, The Discourse Strategy. A deliberative linguistic approach, 1st Edition, Beirut: United Book House, 2004.

[24] Ali Abboud Al-Muhammadawi, The Political Problematic of Modernity. From the philosophy of the self to the philosophy of communication, Baghdad: Adnan Library, 2015.

[25] Ayad Bilal, Anthology of Literature. An anthropological study of the Arabic narrative, Cairo: Rawafed for publication and distribution, 2011.

[26] Marvin Carlson, Performing Arts. Critical Introduction, Trd. Mona Salama, 1st floor, Cairo: Hala House for Publishing and Distribution, 2000.

[27] Mark Jimenez, Maljali, Tr: Dr. Charbel Dagher, 1st floor, Beirut: The Arab Organization for Translation, 2009. 
[28] A Group of Russian Critics, Culture and the Science of Culture in the Twentieth Century, see: Hoda Ali Abd, Baghdad: Dar Al-Ma'moun for Publishing and Distribution, 2010.

[29] A group of authors, Studies in Egyptian theater, Cairo: Ministry of Culture, d.

[30] Muhammad Abu Douma, The transformations of the theater scene, actor and director, Cairo: The Egyptian General Book Authority, 2009.

[31] Mohamed Abdel Moneim, director at the Political Cabaret Theater, Cairo: The Egyptian General Book Authority, 2013.

[32] Natalie Piffy-Gross, An Introduction to Intertextuality, Tr: Abdul Hamid Burayo, Damascus: Nineveh House for Studies, Publishing and Distribution, 2012.

[33] Identity and its Issues in Contemporary Arab Consciousness, edited and presented by: Riad Zaki Kassem, Beirut: Center for Arab Unity Studies, 1st Edition, 2013.

[34] Elias Kante, Masses and Power, Tr: Muhammad Abu Rahma, Cairo: The National Center for Translation, 1st Edition, 2018. 